Original Research Paper

\title{
Pengoptimalisasian Pemasaran Kerajinan Tangan Desa Pendem
}

\author{
Salman$^{1}$, M. Alvin Maulana ${ }^{2}$, Emmy Dyah Soelistyowati ${ }^{3}$, Vivien Silvia $^{4}$, Sri Ayu Dwi Santika ${ }^{5}$ \\ ${ }^{1}$ Jurusan Teknik Mesin, Fakultas Teknik, Universitas Mataram, Mataram, Indonesia \\ ${ }^{2}$ Jurusan Teknik Mesin, Fakultas Teknik, Universitas Mataram, Mataram, Indonesia \\ ${ }^{3}$ Jurusan Teknik Mesin, Fakultas Teknik, Universitas Mataram, Mataram, Indonesia \\ ${ }^{4}$ Jurusan Agribisnis, Fakultas Pertanian, Universitas Mataram, Mataram, Indonesia \\ ${ }^{5}$ Jurusan Teknik Manajemen, Fakultas Ekonomi dan Bisnis, Universitas Mataram, Mataram, Indonesia
}

https://doi.org/10.29303/jpmpi.v3i2.868

Sitasi: Salman., Maulana, M. A., Soelistyowati, E. D., Silvia, V., \& Santika, S. A. D. (2021). Pengoptimalisasian

Pemasaran Kerajinan Tangan Desa Pendem. Jurnal Pengabdian Magister Pendidikan IPA, 4(3)

\section{Article history}

Received: 15 Juli 2021

Revised: 31 Juli 2020

Accepted: 16 Agustus 2021

*Corresponding Author: M.

Alvin Maulana, Jurusan

Teknik Mesin, Fakultas

Teknik, Universitas Mataram,

Mataram, Indonesia

Email:

wsnatacoco5@gmail.com

\begin{abstract}
Abstrak: Kerajinan tangan dari Desa Pendem, Kabupaten Lombok Tengah, Nusa Tenggara Barat, dari segi ekonomi, khususnya pemasaran, belum maksimal karena sejumlah kendala. Oleh karena itu, tim Kuliah Kerja Nyata Tematik Universitas Mataram berinisiatif untuk mengoptimalkan pemasaran hasil kerajinan Desa Pendem. Metode yang digunakan adalah dengan melakukan bimbingan pemasaran online dari produk kerajinan mereka. Hasilnya, para mitra sangat antusias dan bersama tim KKN Unram melakukan kegiatan pemasaran online atau digital marketing. Dengan adanya digital marketing pengrajin dapat menjual produknya tanpa terhalang permasalahan komunikasi akibat pembatasan antar daerah.

Kata kunci: KKN; Pemasaran online; Desa Pendem; Kerajinan tangan
\end{abstract}

\section{Pendahuluan}

Pertumbuhan ekonomi provinsi Nusa Tenggara Barat (NTB) tahun 2020 meningkat dibanding tahun sebelumnya yaitu berada berada pada kisaran hingga 5,6. Berdasarkan data Dinas Koperasi NTB jumlah pelaku Usaha Mikro kecil dan Menengah (UMKM) NTB sebanyak 653.000 orang. Jumlah ini terus bertambah dengan jumlah tenaga kerja yang terserap lebih dari 1,8 juta orang (BPS, 2021).

Perkembangan UMKM di provinsi NTB cukup baik. Hal ini ditunjukkan dengan serapan Produk Domestik Regional Bruto (PDRB) di sektor UMKM sebanyak 4,9\% dari total PDRB NTB pada tahun 2016. Ini menunjukkan bahwa sumbangan UMKM terhadap pertumbuhan ekonomi NTB dan peningkatan ekonomi masyarakat cukup signifikan (Sri, 2017).

Salah satu UKMM yang turut menunjang pendapatan daerah adalah usaha kerajinan tangan di Desa Pendem, Kecamatan Janapria, Kabupaten Lombok Tengah, Nusa Tenggara Barat. Desa Pendem merupakan desa sentra kerajinan karena memiliki banyak kerajinan tangan seperti ketak, bambu, rotan dan karung goni. Kerajinan yang dihasilkan berkualitas dan menjadi salah satu pendapatan utama bagi masyarakat di sana. Namun, semenjak merebaknya pandemi Covid-19 yang bukan saja menyerang kesehatan masyarakat secara global namun juga merugikan sejumlah besar distribusi hasil produksi UMKM termasuk di NTB. Akibatnya sejumlah besar 
hasil kerajinan tangan di Desa Pendem tidak bisa dipasarkan sehingga stock menumpuk di tempat pengrajin. Akibat selanjutnya sebagian produk berjamur sehingga menurunkan kualitas produk.

Salah satu solusi dari permasalahan ini adalah dengan mengoptimalkan sejumlah usaha pemasaran kerajinan tangan di Desa Pendem termasuk pemasaran secara online. Hal ini dilakukan guna lebih mengenalkan hasil produksi secara global.

Untuk itulah tim KKN Tematik Unram melakukan kegiatan pendampingan terhadap UMKM di Desa Pendem dalam bentuk penyuluhan disertai pembimbingan cara pemasaran hasil produk dengan memanfaatkan fasilitas pemasaran online

\section{Metode}

Optimasi hasil pemasaran menjadi fokus utama tim pelaksana pengabdian. Tim melakukan pembimbingan ke pengrajin mulai dari pembuatan akun digital marketing, pengemasan yang dapat menambah nilai jual dari kerajinan, dan pemasaran yang dilakukan melalui situs online yang diyakini mampu meningkatkan kuantitas pemasaran dan pendapatan ekonomi dari pengrajin.

Tim pelaksana melakukan kerja sama dengan perangkat desa. Pola pelaksanaan program dilakukan sebagai berikut:

\section{Survey Lapangan}

Tim pelaksana melakukan kunjungan ke sejumlah pengrajin kerajinan tangan di Desa Pendem. Tim mendata dan menganalisa cara pemasaran yang ditempuh oleh pengusaha kerajinan (Gambar 1). Dari survey ini diperoleh informasi bahwa para pengrajin masih mengandalkan penjualan secara konvensional. Sehingga hasil penjualan tidak optimal. Karena itu mereka perlu melakukan metode pemasaran lain dengan cara digital. Tim lalu meminta kesediaan aparat desa untuk diajak kerjasama dalam penyuluhan demi perbaikan pemasaran hasil produksi.

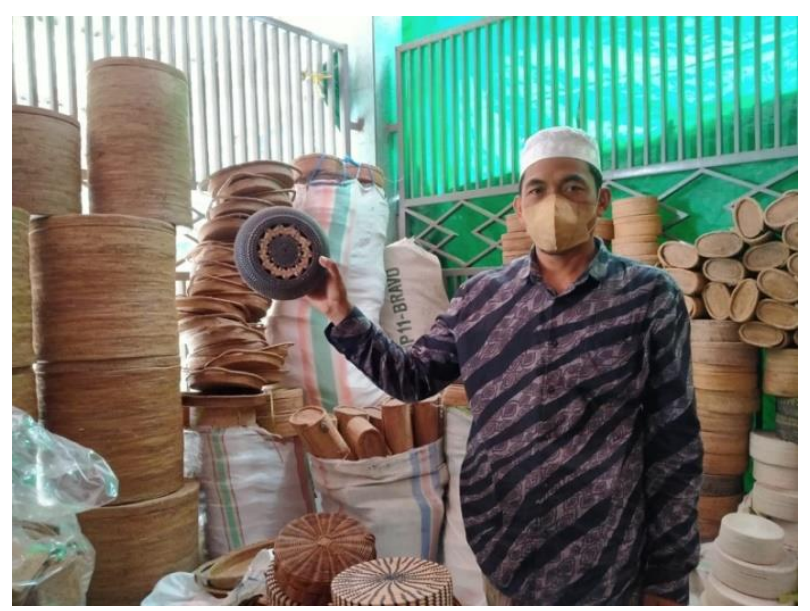

Gambar 1. Salah seorang pemilik usaha kerajinan tangan di Desa Pendem, Lombok Tengah.

\section{Waktu dan Tempat Pelaksanaan}

Penyuluhan dilakukan pada tanggal 10 Juli 2021 berlokasi di Desa Pendem, Kecamatan Janapria, Kabupaten Lombok Tengah.

\section{Penyuluhan}

Penyuluhan dilakukan oleh tim pelaksana pengabdian di depan pemuka masyarakat, aparat desa, pengrajin dan masyarakat umum. Dihadiri sekitar 20 orang. Kegiatan penyuluhan berlangsung dari jam 09.00 sampai jam 12.00 WITA. Dibuka oleh Kepala Desa Pendem dengan pemateri dari anggota KKN Unram. Materi penyuluhan adalah pengenalan digital marketing, cara pembuatan akun dan infromasi lainnya berupa perbaikan pengemasan produk. Selanjutnya tim pelaksana melakukan pembuatan katalog untuk menambah keterangan barang dan harga terhadap produksi kerajinan tangan.

\section{Monitoring dan Evaluasi}

Setelah sosialisasi berjalan, tim pelaksana melakukan monitoring dan evaluasi terhadap pembuatan akun digital marketing. Monitoring dilakukan dengan cara menanyakan langsung kepada pengrajin perkembangan 
penjualan setelah melakukan digital marketing. Evaluasi dilakukan dengan cara membandingkan hasil penjualan baik secara konvensional (tidak melalui online) dan dengan penjualan secara online.

\section{Hasil dan Pembahasan}

\section{Perbaikan Kemasan Produk}

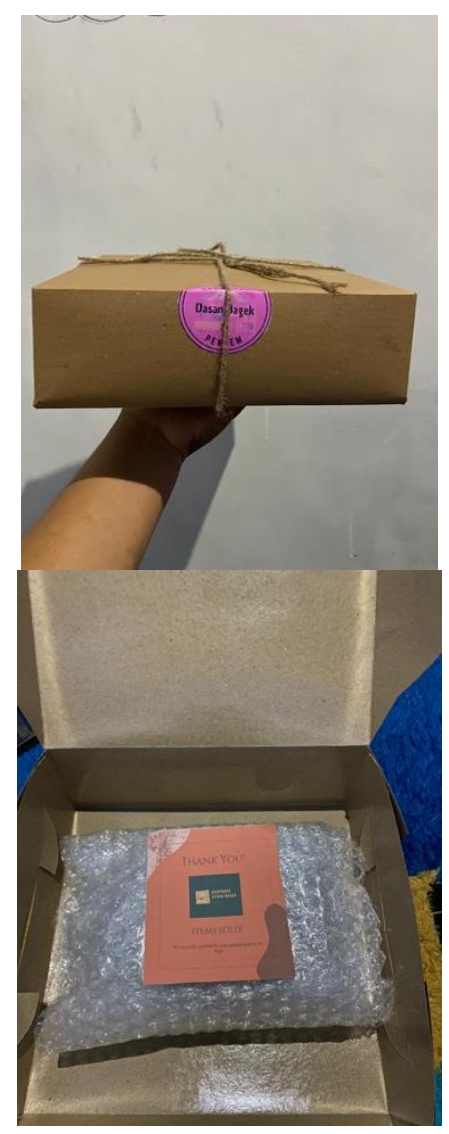

Gambar 2. Tampilan produk setelah dilakukan perbaikan pengemasan atas arahan tim pelaksana kegiatan pengabdian.

Salah satu bentuk hasil kegiatan adalah adanya pebaikan penampilan kemasan produk kerajinan tangan guna menambah nilai jual produk dan agar tidak mudah diakui oleh kompetitor lain. Selama ini pengemasan produk kerajijnan hanya menggunakan karung goni yang dari dari segi penampilan kurang menarik. Karena itu penampilan kemasan diperbaiki dengan menggunakan kemasan box karton dalam berbagai ukuran. Ukuran dari box karton yang ditampilkan di Gambar 2 adalah 22 x 20 × $20 \mathrm{~cm}$. Di dalam box terdapat bubble wrap yang berfungsi untuk menjaga produk kerajinan tangan dari benturan, retak, pecahan, dan lain-lain. Sehingga menjaga keamanan produk sampai tujuan. Terdapat sticker sebagai identitas dari kerajinan produk untuk menghindari klaim produk dari pengusaha lain. Disertai juga di dalamnya ucapan terima kasih sebagai tanda terima kasih ke konsumen. Kemasan ini diharapkan dapat meningkatkan nilai jual tambah produk dari segi penampilan.

\section{Pembuatan akun}

Hasil dari kegiatan pengabdian ini adalah sikap antusiasme para peserta kegiatan megikuti penyuluhan (lihat Gambar 3). Mereka serempak membuat akun digital marketing didampingi tim pelaksana. Selain melalui media seperti Shopee penjualan mereka juga memasarkan lewat media sosial seperti Facebook, Instagram, WA dan Twitter. Hal ini membantu meningkatkan pemasaran hasil kerajinan tangan dan kembali mengaktifkan penjualan produk setelah tersendat oleh pandemi. Hasilnya adalah adanya pengetahuan baru mengenai penjualan secara online oleh para pengrajin. Kegiatan pembuatan akun dan pengunduhan materi foto dilakukan menggunakan ponsel atau smartphone. Dengan dibantu tim pelaksana pengabdian para pengrajin berlatih menampilkan hasil kerajinan mereka dalam bentuk dokumentasi atau foto produk dengan tampilan yang menarik konsumen. Mereka juga dilatih memanfaatkan sejumlah fitur pendukung seperti pembuatan email minimal di Google Mail, plat form ecommerce, chat, dan blogspot pribadi. Sejumlah e-commerce yang direkomendasikan untuk memasarkan hasil kerajinan antara lain Tokopedia, Shopee, Bukalapak, BliBli, dan Lazada. Namun dalam pendampingan dan penyuluhan ini para peserta hanya membuat membuat akun di Shopee. Selain itu peserta kegiatan sudah mengetahui sejumlah opsi pembayaran yang dapat mempermudah calon 
pelanggan saat melakukan transaksi secara online. Pengguna media membuat spesifikasi dan diskripsi produk sehingga mudah diakses calon konsumen saat browshing produk.

Dari pembuatan akun digital marketing diperoleh aktivitas pemasaran cara baru oleh pengrajin sehingga pemasaran kembali berjalan setelah sempat terhenti karena adanya pandemi dan pembatasan akses antar daerah.

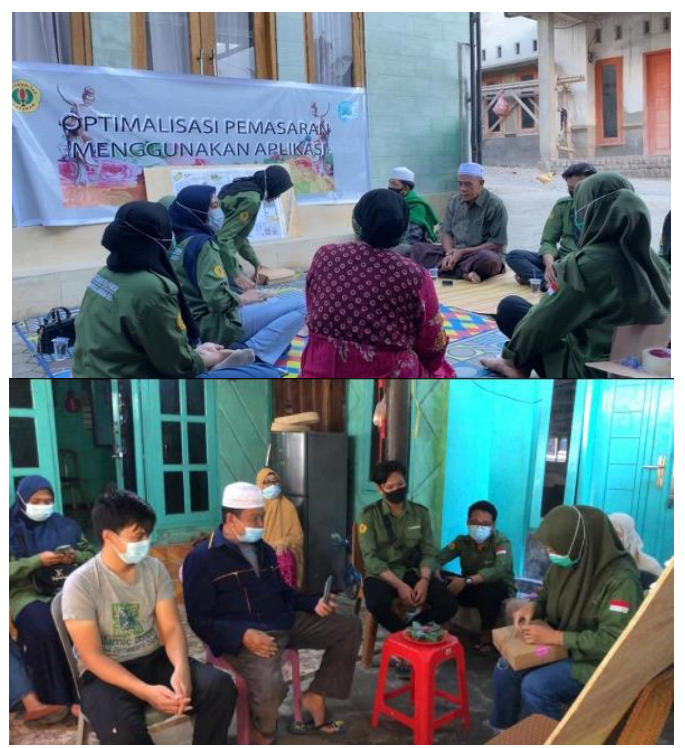

Gambar 3. Suasana kegiatan penyuluhan dan pendampingan pada warga Desa Pendem dan pengrajin.

Sikap atau respon positif dari peserta penyuluha ini dikarenakan terdapat alternatif baru dalam pemasaran produk kerajinan tangan dan sangat efektif dilakukan kapan pun dengan cara yang mudah dan modern, tidak perlu kesulitan memikirkan barang tidak bisa terjual karena pembatasan akses antar daerah karena semua bisa dilakukan melalui ponsel dari pemesanan hingga pemasaran yang dilakukan dengan mudah.
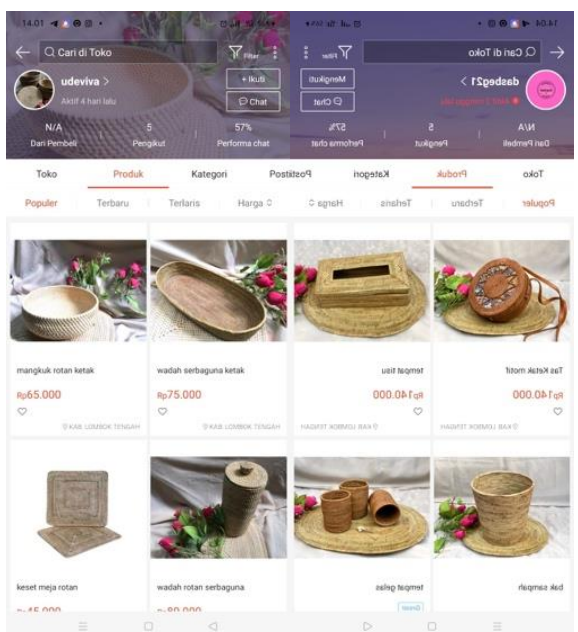

Gambar 4. Tampilan produk kerajinan Desa Pendem dalam bentuk pemasaran online.

Hasil utama yang diperoleh dari kegiatan ini adalah pengrajin sudah mampu mengoperasikan serta memulai berjualan menggunakan media digital marketing dan media sosial (lihat Gambar 4 dan 5). Bagi pengrajin kegiatan ini dapat menambah pengetahuan mereka mengenai digital marketing dan membuat inovasi terkait dengan kemasan produk yang dapat menambah nilai jual barang. Contohnya tas ketak dengan motif cuklik yang berharga Rp100.000 dapat terjual dengan harga Rp 150.000 sehingga bisa menambah pendapatan dan ekonomi pengrajin Desa Pendem.

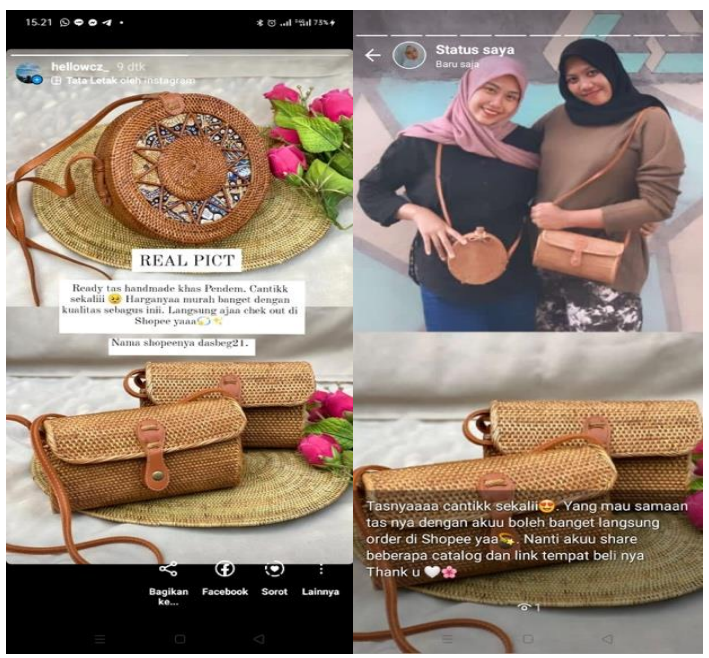

Gambar 5. Produk juga dipasarkan melalui media sosial. 
Dari segi hasil monitoring sampai saat ini tim pelaksana masih terkendala Pemberlakuan Pembatasan Kegiatan Masyarakat (PPKM) sehingga belum bisa diperoleh evaluasi perbandingan hasil penjualan setelah dan sebelum dilakukan penerapan pemasaran secara online oleh pengrajin.

\section{Kesimpulan}

Hasil kerajinan tangan Desa Pendem, Kecamatan Janapria Lombok Tengah cukup bagus dan berkualitas. Hanya saja pemasaran belum dilakukan secara maksimal dan terhambat oleh pandemi. Untuk mengatasi permasalahan ini tim pelaksana pengabdian melakukan pendampingan ke para pengrajin setempat dalam bentuk optimalisasi pemasaran produk. Hal-hal yang dilakukan antara lain memperbaiki kualitas pengemasan produk dan pembuatan akun online digital marketing.

Dengan adanya digital marketing pengrajin dapat menjual produknya tanpa terhalang permasalahan komunikasi akibat pembatasan antar daerah. Hanya saja kekurangannya, mereka masih perlu banyak melatih keterampilan pribadi menggunakan teknologi digital ini.

\section{Saran}

Sebagai saran ke pelaksana kegiatan serupa diharapkan agar melakukan juga perbaikan manajemen lainnya selain dari pemasaran.

\section{Ucapan Terima Kasih}

Penulis mengucapkan terima kasih kepada LPPM Universitas Mataram, Kepala Desa Pendem dan semua pihak yang turut membantu pelaksanaan kegiatan pengabdian ini.

\section{Daftar Pustaka}

Sri, B.M, 2017. Tipologi Kecamatan Tertinggal di Kabupaten Lombok Tengah, Jurnal Teknik ITS Vol. 4, No. 2, p.119-124

Badan Pusat Statistik (BPS), Kabupaten Lombok Tengah, 2020, Kabupaten Lombok Tengah DalamAngka 2021, Praya.

Karinov. 2018. Mengenal Digital Marketting, Pengertian dan Caranya, CV. Dunia Ilmu, Jakarta

http://www.nigahoster.co.id/blog/ide-usahakecil-menengah Diakses pada 31 Juli 2021

Suryani, I. 2014. Pemanfaatan Media Sosial Sebagai Media Pemasaran Produk dan Potensi Indonesia Dalam Upaya Mendukung ASEAN Community 2015. (Studi Social Media Marketing Pada Twitter Kemenparakef RI dan Facebook Disparbud Provinsi Jawa Barat). Jurnal Komunikasi, 8 (2), 122-138.

Yasmin A, Tasneem S, Fatema K. 2015. Effectiveness of DigitalMarketing in the Challenging Age: An Empirical Study. International Journal of Management Science and Business Administration, 1 (5), 69-80. 